\title{
From Hitler's Sweater to Dinosaur Fossils: An Essentialist Outlook on Authenticity
}

\author{
Dylan J. J. van Gerven', Anne M. Land-Zandstra', \\ and Welmoet Damsma ${ }^{2}$
}

\begin{abstract}
Over the past two decades, the concept of authenticity has been the subject of considerable disagreement and debate. Although there have been attempts at reconciling various existing approaches, the literature is still short on a definition that is both practical and precise. This article proposes to make significant headway to that effect by suggesting that authenticity can be accounted for by an underlying psychological phenomenon known as essentialism. In making our case, we first provide an overview of present-day objectivist and constructivist positions and point out their shortcomings, after which we introduce an essentialist account of authenticity. We then argue essentialism has profound benefits over contemporary views and might be the best overarching framework we have, if we intend to reach consensus on the meaning of authenticity.
\end{abstract}

\section{Keywords}

authenticity, objects, essentialism, constructivism, objectivism

\section{Introduction}

Nearly half a billion dollars for a painting. That was the price for which Christie's sold Leonardo da Vinci's long lost painting of Jesus Christ. The enormous sum astounded even the art world itself. Never before had any painting been auctioned at such an extraordinary price (Helmore, 2017). The substantial sum paid for the da Vinci, in a way, epitomizes our relation with authentic objects. We are often more willing to spend a considerable amount of money on originals than on replicas, however well they may be reproduced (Frazier, Gelman, Wilson, \& Hood, 2009).

But despite the ubiquity of authentic objects, authenticity is still very poorly understood, its meaning being the subject of considerable debate. Is authenticity in the object and in principle discoverable (Lau, 2010)? Or is it constructed by the perceiver, and therefore dependent upon context and sociocultural input (Mkono, 2012)? Many questions remain and there seems to be little consensus among researchers as to its meaning, causing the field to break up into a variety of positions (Belhassen \& Caton, 2006; Reisinger \& Steiner, 2006).

The response to these issues has been 3-fold. On one hand, there are researchers who accept the concept's complexity and use multiple approaches to study authenticity (Buchmann,
Moore, \& Fisher, 2010; Rickly-Boyd, 2012a). Whereas, on the other, there are those who devise their own concepts in an attempt to bring together the seemingly incompatible findings. This leads to such concepts as "theoplacity" (the relationship between place, belief, and action) and "pastness," involving the age-value of an object (Belhassen, Caton, \& Stewart, 2008; Holtorf, 2013). Others still refrain from defining authenticity altogether and take to exploring its effects instead (Bendix, 1997, p. 21). Although these diverse outlooks may each have their benefits, they have the adverse effect that few researchers are on the same page when it comes to authenticity, making it more difficult to draw comparisons across studies (Reisinger \& Steiner, 2006).

For this reason, we will here attempt to reconcile current positions, not by implementing yet another novel concept but by suggesting that authenticity of objects can conceivably be accounted for cognitively. This approach

\footnotetext{
'Leiden University, Leiden, The Netherlands

${ }^{2}$ Naturalis Biodiversity Center, Leiden, The Netherlands

Corresponding Author:

Anne M. Land-Zandstra, Department of Science Communication \& Society, Leiden University, Sylviusweg 72, 2333 BE Leiden, The Netherlands.

Email: a.m.land@biology.leidenuniv.nl
} 
was already tentatively examined by Gelman (2013), after which it was further developed by Newman (2016) and is known by the name of psychological essentialism. We believe essentialism can be used to define the concept of authenticity and take this to be the purpose of the present article.

This article is divided into three main sections. In the first section, we will give a brief summary of objectivism and constructivism, the two most dominant positions in the discourse on authenticity. Next, we will dwell on the shortcomings of both views and examine why many solutions ultimately fall short of providing a definition that is both practical and empirically robust. In the second section, we introduce an essentialist account of authenticity as a viable alternative to current definitions and show how essentialism ties together previous seemingly irreconcilable findings. The limitations and unresolved questions will be dealt with in the third and final section.

But before we move on, it will be necessary to stake out the scope of our endeavor. First of all, the vastness of the literature on authenticity precludes us from dealing comprehensively with all relevant domains. In this article, we will therefore concentrate our efforts mainly on the authenticity of objects, in part because their authenticity is in need of a more stable theoretical footing. Second of all, we take authenticity to be a concept. By concept, we mean a mental representation that organizes experience and includes categories of things in the world, such as tables and chairs, properties (green, happy), individuals (Daddy, Lassie), and abstract ideas (goodness, liberty; Gelman, 2009). We further take an object to mean any physical thing or artifact that can easily be delineated. ${ }^{1}$ We do not, for this reason, consider performance art, music, or experiences to be objects in our sense. Existential authenticity (see Rickly-Boyd, 2012b; Wang, 1999) therefore falls outside the bounds of this article. We also exclude virtual projections and living things, although the latter can, without a great many problems, be assimilated into the current framework.

\section{Objectivism and Constructivism}

At least two different views have been dominant in the discourse on authenticity, commonly referred to as objectivism (or materialism) and constructivism (Holtorf, 2013). Of these two, the oldest and most traditional is the objectivist approach, which finds its origins in the museum: "As we use it in reference to human existence, its provenance is the museum, where persons expert in such matters test whether objects of art are what they appear to be or are claimed to be" (Trilling, 1972, p. 93). According to objectivists, authenticity is a real, objective feature of the object, which can in principle be discovered by careful study (Wang, 1999). Proponents of this view further maintain that the meaning of authenticity lies in all that is real, genuine, unadulterated, and accurate (Reisinger \& Steiner, 2006).

Although objectivism is now looked upon less favorably by academics than it was 40 years ago, there are still some contemporary scholars who employ the concept in their studies (Chhabra, 2012; Lau, 2010). In museums as well, some modern curators continue to define authenticity in objectivist terms (Chhabra, 2008). As one curator put it,

Artefacts are assumed to be authentic because they can be shown to have been found in their original context, because high-tech research methods have "proven" the authenticity of a piece or, as is the case for most objects that are acquired on the art market, simply because they "fit the style." (Berger, 2013, p. 28)

In committing to a realist position, objectivists usually make a sharp distinction between originals and their copies (Chhabra, 2012). Constructivists, however, make no such distinction. Their conception of authenticity is rather more fluid. For them, authenticity is not an objective property of the object, but instead something that is socially constructed (Wang, 1999). Authentic objects, in their sense, are a product of one's perspective, context, or expectation and are therefore not held to be universally accessible (Mkono, 2012). Constructivists thus focus on an object's perceived authenticity. For them, there is no "reality or truth" to authenticity that can be discovered through scholarship because authenticity is a negotiable trait (Cohen, 1988).

In the present-day discourse on authenticity, the two stances are still apparent. Some scholars are largely objectivist (Lau, 2010), whereas others lean more toward the constructivist view (Rossi, 2010) and many are somewhere in between (Belhassen et al., 2008; Holtorf, 2013; RicklyBoyd, 2012a). Yet both of these positions have their limitations. In the next section, we will address some of these shortcomings.

\section{Drawbacks of the Two Views}

Before being eclipsed by constructivism, objectivism once held wide appeal. Its central claim was straightforward: Authenticity is a real property of objects that can be measured against objective criteria (Wang, 1999). Such a definition had the advantage of being clear and concise and, to this day, remains an integral component in modern adaptions of objectivism (Chhabra, 2012). Nevertheless, there are a number of drawbacks that seriously constrain any objectivists account of authenticity.

One of the major critiques of objectivism is its neglect of context. If authenticity were an entirely objective property, we would expect that an object's authenticity should remain unaffected by context as it is inherent in the object itself. But we often find the opposite to be true; context frequently influences the authenticity of objects and sometimes alters 
it completely. In a study by Bunce (2016), museum visitors were asked about the authenticity of a taxidermied rabbit in different conditions. Her findings revealed that when participants could only see the rabbit behind glass, they judged it to be more authentic than when they were allowed to touch the taxidermied animal. Interestingly, the number of people who believed the rabbit to be real increased even more when it was accompanied by a toy rabbit, and both were allowed to be touched. This shows that the perceived authenticity of an object is influenced by the setting in which it is placed. An object that is considered to be authentic in one given environment can be less authentic when placed in another setting.

To this observation, objectivists respond by arguing that context only affects our knowledge about the object, which they claim is not the same thing as its actual authenticity (Lau, 2010). Here, the all-important difference is between perceived and objective authenticity; between people's lay beliefs and the judgment of experts who are believed to have independent access to the "true nature" of authentic objects. Yet the search for this common core, unique to all authentic objects, has revealed that there may in fact be no such thing (Reisinger \& Steiner, 2006). Consider, for example, the distinction between natural and synthetic diamonds. Natural diamonds are often viewed as authentic and thought to have an inner constitution that differs from those of synthetic imitations. In reality however, no such difference exists because technological advances have made it possible to produce diamonds that are both chemically and physically identical to natural ones (Leslie, 2013). The difference is therefore not so much in the world as it is "in the head."

We are running into some deeper issues here on what it is that makes a particular object that object. Although this article is not the place to go into details, we would like to make one general point, which is that the notions of objecthood and object identity have profound complications for the objectivist. ${ }^{2}$ Latour and Lowe (2010) remind us of the well-known fact that even for any work of art to subsist, it needs to be dusted, reframed, and restored. Paradoxical as it may seem, a painting must therefore be continually reproduced to survive. But does this mean the painting after restoration $i s$ the same painting as the one before? Or take Hess' (2017) example of the BBC's first radio transmitter. Before being on display at the Science Museum in London, the apparatus was frequently altered, adapted, and repaired during its working life. The apparatus, in fact, "collected baggage" along the way. Are these components objectively less authentic than the original ones? And what about the work of Piero Manzoni? His white cotton "Achromes" were originally intended to be periodically washed or overpainted, but many owners instead opted for its preservation and, in doing so, went directly against Manzoni's express wishes (Lowenthal, 1992). Which "Achrome" one considers to be more authentic depends on whether one privileges the artist's intentions over the preservation of the object (Sandis, 2016).

These examples show us two things. First, authenticity cannot be objectively defined because authentic objects, like natural and synthetic diamonds, do not have an inner "true nature" (Leslie, 2013). And second, what holds an object together, such as the BBC's radio transmitter, is not so much the material itself, as well as our social construction of the object (Hess, 2017).

This focus on the social aspects of authenticity is characteristic of constructivist scholars who often question the objectivist's materialistic approach to authenticity (Bruner, 1994; Cohen, 1988; Cohen-Aharoni, 2017). In a thoughtful study on the craft of restoration binding, Rosner and Taylor (2012) highlight the difficulty of the objective stance. In their view, social aspects are as much part of the object as its material features:

What counts as authentic is thrown into doubt when we consider that age is worked into an antiquarian book. If particular aspects of a book's age can be purposefully ignored, actively preserved, repaired with the future in mind and so on, then what, exactly, should be identified as valued or authentic? Is it the book itself, the material, the workmanship, or some combined configuration of each? The likelihood is that, as with age, authenticity is a crafted quality assembled and continually shifting through a network of relations ... (p. 420)

Thus, according to Rosner and Taylor (2012), authenticity is not solely bound up in the object's material but subject to human interactions with the object instead. In other words, authenticity is at least partly constructed by the perceiver.

Studies on consumer behavior take a similar view to authenticity. For example, in a series of interviews with wine consumers, Beverland (2006) reveals that the authenticity of wine depends as much on real properties of the wine as it does on other subjective features, such as the downplaying of commercial interests or stylistic consistency.

Findings by other researchers corroborate this interplay between the real and the contrived. For instance, Grayson and Martinec (2004) found that visitors of Shakespeare's birthplace and the Sherlock Holmes Museum assessed the authenticity of the two sites in similar ways, despite Sherlock Holmes being a fictional character. In both studies, people did not presuppose some universal standard but were rather actively constructing authenticity (Beverland \& Farrelly, 2010).

Constructivist approaches like those of Rosner and Taylor (2012) and Beverland (2006) have several advantages. First, they are not susceptible to the same pitfalls as objectivism as they rely on people's subjective experience rather than on objective, discoverable qualities. Second, they have proved a useful framework for studying the factors underlying authenticity (Felker, Hammond, Schaaf, \& Stevenson, 2014; Hampp \& Schwan, 2015). And third, 
constructivism is very versatile, allowing for more than one perspective or process of meaning-making (Wang, 1999).

Yet in spite of its advantages, constructivism has not yielded a consensual definition either. One of the reasons why such a definition is lacking is that, as an approach to capturing the essence of authenticity, constructivism is too unconstrained (Reisinger \& Steiner, 2006). Indeed, constructivist scholars often use very flexible and open-ended definitions in their characterization of authenticity. They describe it as being relational (Rickly-Boyd, 2012a) or negotiated by a diverse set of stakeholders (Felker et al., 2014; Mkono, 2012; Rossi, 2010).

Such definitions may work very well academically, but their versatility hampers them from being universally applied (Reisinger \& Steiner, 2006). For instance, many American museum curators are still firmly embedded in the objectivist tradition (Chhabra, 2008), and the practical authentication of archeological objects is performed by technological investigation, not sociological analysis (Michalopoulou, Adam-Veleni, \& Karapanagiotis, 2017). The constructivist's suggestion that the authenticity of ancient objects is a contemporary cultural construct therefore seems to be of little use in these areas (Holtorf, 2013).

Another criticism of constructivism is that it has little regard for the materiality of objects (Holtorf, 2013). Constructivists normally treat authenticity as being more or less independent from the physical object. But empirical evidence challenges this independence. For example, in a constructivist study on the authenticity of an ancient monumental cross-slab and its full-scale reconstruction, Jones (2010) revealed that during production of the replica, local people collected leftover fragments from the studio in which the monument was made, for the purpose of proudly displaying them at home. The seemingly ordinary pieces of stone thus carried special significance, as if they contained within themselves some numinous quality, ${ }^{3}$ resulting in a strong desire to touch and own these fragments (Jones, 2010). Apparently, the authenticity of these fragments was believed to reside in their material. It is therefore unlikely that authenticity is completely independent from the physical object as the constructivists claim.

The desire to touch an authentic object and the feeling that it embodies some deeper quality, as reported by Jones (2010), are vitally important, and similar experiences have been reported in a number of other studies as well (Buchmann et al., 2010; Hood \& Bloom, 2008; Latham, 2013; van, Gerven, Land-Zandstra, \& Damsma, 2018). In all these instances, the physical aspect of the objects was clearly important for people's appreciation of authentic objects.

\section{A Problematic Middle Ground}

With both objectivism and constructivism being problematic, it might naturally be assumed that a position somewhere in between should hold up better. Unfortunately, the definitions from studies which aim to strike a compromise between the two extremes are often subject to the same limitations described above. An example of such a hybrid approach is the study of Holtorf (2013), who adapted the constructivist position, so that it would acknowledge the material qualities of objects. Instead of concentrating on the age of an object, he proposes that we should focus on its "age-value" or "pastness" and use this concept as a definition of authenticity (Holtorf, 2013). Although a full exposition of his argument is beyond the scope of this article, we will briefly summarize his three requirements here.

First, Holtorf (2013) mentions that pastness requires material clues such as patina, cracks, traces of disintegration, and so on. Thus, when an object is lacking in material clues, it may cease to be perceived as of the past. Second, Holtorf (2013) asserts that there needs to be a correspondence between our preconceptions and the way an object actually looks. This is why contemporary models of Greek temples often look old, and not brightly colored as they were originally because brightly colored temples would not possess the pastness required for their authenticity (Holtorf, 2013). Holtorf's (2013) third and final condition is that pastness needs a credible story linking past to present. If such a story is lacking, or does not make sense, people begin to doubt the pastness of the object (Holtorf, 2013). For example, objects attempting to prove that some prehistoric dinosaur inhabits lake Loch Ness would lack in pastness, for the reason that the presence of such a creature does not conform to modern evolutionary insights.

It is important to view Holtorf's (2013) argument in the light of his project, which is to adapt the constructivist approach to authenticity, so that it makes up for its lack of concern for the material qualities of objects. The real question is not whether he succeeds at this, but whether his definition is able to overcome the limitations of constructivism and can thus be developed into a full-fledged account of authenticity. Unfortunately however, pastness suffers from both limitations of constructivism. For one thing, it does not apply to objects lacking in pastness and, by extension, to old objects that fail to appear aged such as the Regent Diamond in the Louvre. But it is also too unconstrained because according to pastness, any object with sufficient age-value would immediately be authentic. Does any oldlooking object with a credible backstory qualify?

Finally, under the assumptions of pastness, two identical looking objects should have a similar age-value and hence be equally authentic. However, in an insightful study, Marchak and Hall (2017) demonstrated that other factors than appearance alone determine people's perceptions of authenticity. Participants were told that an object (e.g., a piano or tennis racquet) had been used by a well-known celebrity. Components of the object were then gradually replaced by new parts which had not been in contact with the celebrity, whereas the old parts were used to recreate the 
original object. This resulted in two items: one consisting of the original material (the old-parts object) and the other being made up of entirely new components (the new-parts object). The researchers found that people judged the oldparts object to be significantly more authentic than the new parts object, which had not been in contact with the celebrity. Interestingly, the difference in authenticity between the two objects largely disappeared when participants were told the celebrity continued to use the object during the transformation. Celebrity contact was therefore found to be the crucial factor affecting the authenticity of the objects.

This so-called celebrity effect has been reported in several other studies and has been extended to include artists, dinosaurs, and locations (Newman \& Bloom, 2012, 2014; Newman \& Dhar, 2014; Newman, Diesendruck, \& Bloom, 2011; van Gerven, Land-Zandstra, \& Damsma, 2018). Thus, as we have previously seen in Jones (2010), authentic objects seem to acquire some numinous-like quality as a result of the "ineffable contact of past relations," which is believed to be embodied by the object (Jones, 2010). Pure objectivism, constructivism, as well as pastness and other hybrid models of authenticity are currently unable to explain these effects.

\section{Essentialism}

The following section introduces the cognitive bias known as psychological essentialism. It begins by providing a brief description of the theory and continues with an overview of its defining characteristics. Next, we draw a parallel between essentialism and authenticity to demonstrate how they are related.

Psychological essentialism is the view that certain categories are thought to have a deeper underlying reality, called an "essence." It entails the deeply ingrained belief that above and beyond their superficial appearance, some categories of our understanding (e.g., dogs, tigers, silver) possess an inner causal core ${ }^{5}$ responsible for their identity and underlying features (Gelman, 2004). For instance, when you are aware that some insect is a caterpillar, you can infer that it will become a butterfly rather than a dragonfly.

Importantly, essentialism does not require knowledge of what it is that constitutes the essence. It could be DNA, a molecular composition, or something else altogether. Rather, the essence often functions as a causal placeholder; someone may believe two members of a category share the same essence without actually having specific knowledge of what it is that makes up the essence (Medin \& Ortony, 1989). For example, 4-year-olds express the belief that boys are, in some unknown way, internally different from girls and infer that this difference is responsible for gender-linked properties, such as wanting to play football (Gelman, 2003, p. 96).

It is also worth noting that essentialism does not imply the existence of essences "out there" in the world. It instead merely reflects the psychological belief that essences exist and is therefore more like a lay belief or reasoning heuristic than a metaphysical conviction. Indeed, our essentialist tendencies sometimes lead us astray, such that we take particular social categories (e.g., race, ethnicity) to reflect natural kinds with hidden essences (Diesendruck \& Menahem, 2015; Gil-White, 2001; Heine, Dar-Nimrod, Cheung, \& Proulx, 2017; Prentice \& Miller, 2007).

Essentialist beliefs have several empirical consequences. The first of these is inherence. In essentialized categories, unobservable properties take precedence over perceptual ones. In other words, there is a difference between looking and being the same. Appearances can be deceiving, whereas internal features are often more informative for categorization (Gelman, 2003). For instance, sharks look more like dolphins than goldfish do. Yet the dolphin is anomalous because it is a mammal and not a fish. Similarly, fool's gold is not really gold, even though it may appear as such. Therefore, having deeper knowledge about the insides or essence of something eases the process of categorization.

A second characteristic which follows from the attention on invisible features is that essences are highly informative and therefore enable us to make novel inductive inferences (Gelman \& Markman, 1987). When you know two animals belong to the same category (e.g., terriers and golden retrievers are both dogs) you can extend one property (such as food preferences) from one dog to another on the assumption that they share the same essence (Tarlowski, 2018).

A third aspect of essentialism is that its categories are treated as being relatively discrete. Something either does or does not belong inside a category and is not somewhere halfway in between. For instance, we say a penguin is a bird, not that it is a half-bird or bird-like, despite the fact that it looks atypical as far as birds are concerned. This is called boundary intensification because of our tendency to intensify category boundaries and draw them closer than they really are (Gelman, 2003, p. 67).

\section{Essence and Authenticity}

The relation between essentialism and authenticity is a rapidly emerging field of study with outgrowths in a wide variety of domains, spanning from art to artifacts and up to people. Recent findings in fact suggest that essentialism underlies people's intuitions about their personal identity or "true selves" (De Freitas, Cikara, Grossman, \& Schlegel, 2018). These selves are believed to be morally good and exhibit all the hallmarks of essentialistic reasoning (Christy, Schlegel, \& Cimpian, 2017; Strohminger, Knobe, \& Newman, 2017).

But other domains, such as that of artifacts, are typically less susceptible (Greif, Kemler Nelson, Keil, \& Gutierrez, 2006; Rhodes \& Gelman, 2009). We do not, for instance, speak of chairs as having some inner "chairness." Artifact 
categories are mutable; chairs can be turned into stools, and stools into side-tables, and so on. Moreover, artifact categories have indistinct, fuzzy boundaries. We often say tables and sofas are furniture, but whether candles and ash trays belong to the same category is less clear-cut.

Although essentialism in its full form does not apply to artifact categories (e.g., spoons in general), ${ }^{6}$ there is evidence that individually (e.g., the Queen's spoon), authentic objects are prone to the essentialist bias (Gelman, 2013). This is because during transformation from one category into another, authentic objects are believed to retain some inherent quality, or essence. Nemeroff and Rozin (1994) give the example of Hitler's sweater. Theoretically, such a sweater can be reknitted into a scarf and thereby change its category. But the newly made scarf will still be imbued with its previous history, causing people to feel reluctant when asked to wear it (Nemeroff \& Rozin, 1994). Two authentic objects can therefore look the same (such as Hitler's sweater and an ordinary sweater), but this does not mean that people believe that they are the same as the two sweaters do not share the same "essence."

Conflicts between appearance and reality are rife in authenticity. There are natural and artificial diamonds, original paintings and facsimiles, real fossils and plaster reproductions and replicas of replicas. The point is not that people distinguish between originals and replicas on the basis of an underlying essence. That would be objectivist thinking, and moreover very difficult to accomplish for the reason that people generally have no clear idea what the essence is made up of. The point is rather that they believe the identity of a valued object to reside in its essence. Put differently, people value some objects more than others, and to ensure that they continue to value the same object, they construe an essence, which allows them to track the individual through space and time ${ }^{7}$ (Gelman, 2013).

This is an essentialist account of authenticity, and even though applying essentialism to authenticity is a relatively new idea, there are several lines of evidence which show that authentic objects are believed to have a deeper underlying reality.

First, authentic objects are often highly valued for their unobservable properties (Frazier et al., 2009). When a given object has a significant history, such as a rock from the moon, or a tuxedo worn by Pierce Brosnan, people judge it to be more worthy of being placed in a museum; rate it as being more desirable, having higher monetary value; and also express a stronger desire of wanting to touch the object (Frazier et al., 2009). For most objects, these effects hold cross-culturally and are also found in young children, thereby reducing the possibility that it is in some way learned or culturally acquired (Frazier \& Gelman, 2009; Gjersoe, Newman, Chituc, \& Hood, 2014). In fact, we now have evidence showing that children as young as 3 years of age are capable of placing special value on unique individuals and understand the subjective nature of that value (Gelman \& Davidson, 2016). Furthermore, the relationship between authenticity and an object's unobservable features appears to be positive, so that when the authenticity of an object is high, the degree to which it is valued for its unobservable properties will also be high (Newman, 2016).

A second characteristic which essentialism shares with authenticity is that it allows for novel inductive inferences. When two perceptually dissimilar authentic objects are from the same source, people infer that they share a novel property (Newman, 2016). For example, two paintings produced by the same painter are both judged to have an inexplicable quality called "Goudire" and two rocks from the moon are both believed to contain the same mineral (Newman, 2016).

A third reason why essentialism is compatible with authenticity is that authentic objects are subject to boundary intensification. The authenticity of objects does not run from the inauthentic to the authentic in a continuous manner but is instead viewed as being relatively discrete. Hence, any change in the essence of an authentic object leads to a disproportionately large reduction of its authenticity, whereas structural alterations have little effect (Newman, 2016; van Gerven et al., 2018).

A fourth and crucial feature authentic objects must possess if they are essentialized is the capacity (of the essence) to have causal consequences. Lee, Linkenauger, Bakdash, Joy-Gaba, and Profitt (2011) explored this issue by examining the performance of two groups of golfers. One group was led to believe they were using the putter of a famous golfer, whereas the other was told they were given an ordinary putter. Participants who believed the putter had belonged to a famous golfer outperformed those who did not and also perceived the size of the golf hole to be larger. Other evidence for the causal effects of essences comes from the previously discussed study of Nemeroff and Rozin (1994). The reluctance people reported when asked to wear a sweater from someone evil, like Hitler, was not only due to association or the symbolic meaning implied by the object but also for a large part to the transmission of the person's essence. Participants strongly felt the object would somehow "pick up negativeness" (Nemeroff \& Rozin, 1994). These results suggest that essences can have causal effects beyond increasing the market value of an object.

In sum, authentic objects are objects believed to have an underlying reality that cannot be observed directly and which sets them apart (boundary intensification) from other similar-looking objects. This underlying reality can be viewed as a conceptual placeholder, allowing for inductive inferences and causal effects.

Although there might be more ways of making sense of these findings, we believe that an essentialist reading is most plausible. To echo Newman (2016), we propose that authentic objects are thought of as having an essence. We value these objects because we value the essence, and it is 
the object that reflects this essence. In short, an authentic object can be operationally defined as being authentic to the extent to which it embodies some valued essence (Latham, 2009; Newman, 2016).

\section{Contrasting Essentialism With Objectivism and Constructivism}

So how does essentialism size up against objectivism and constructivism? For one, it is able to explain the dichotomy of the objectivists. Their distinction between the authentic and the inauthentic is in accordance with the essentialist perspective because essentialism predicts that the boundaries between what is authentic and what is not should be relatively discrete. This does not mean, however, that authenticity is again a question of absolutes; of hard lines between originals and replicas. Different people may have different perceptions. There is the influence of context, of culture, and of emergence: The ordinary today might be authentic tomorrow. All essentialism maintains is that the authenticity of objects can be settled empirically by determining the extent to which they are believed to reflect a valued essence, and whether these objects are replicas or not makes little difference.

Such an approach at once dissolves the problems of objectivism because it does not depend on the problematic claim that authenticity is a real objective feature. For example, the taxidermied rabbit from the study by Bunce (2016) referred to earlier would arguably be authentic from an objectivist point of view, even though context demonstrably affected its perceived authenticity. Essentialism would allow for this effect because it predicts that perceptions of authenticity are linked to perceptions of essence. Hence, the participants who judged the rabbit to be authentic in one condition should have been more likely to construe an essence than those who judged the animal to be inauthentic in another condition.

The position we advocate is also impervious to the drawbacks of constructivism because it is not as unconstrained. Essentialism is no all-purpose framework but a practical theory with clear empirical predictions. Unlike constructivism, there is consensus on its basic principles, making it possible to reach general agreement on a definition of authenticity for objects. This would allow us to provide an answer to some constructivist questions raised earlier, such as Rosner and Taylor's (2012) remark about what, exactly, should be identified as valued or authentic? As we would have it, the answer would be the essence. In practice this would have to be accomplished by means of some essentialist index, which could be computed using the set of predictions we have laid out in this article (see also Newman, 2016).

And finally, essentialism is able to accomplish what other hybrid models could not: to fully account for the numinous-like qualities and celebrity effects reported by
Jones (2010), Latham (2013), and Newman and Bloom (2014). Constructivism here ran into trouble because it assumed that authenticity was independent from the object. As the above-mentioned authors demonstrated, people do not give credence to this independence but rather believe that authenticity inheres in the object as if it has pervaded the object through and through. This is in line with essentialist thought as essentialism adopts a physical model of how essences persist over time (Newman, Bartels, \& Smith, 2014). Once people believe an object has an essence, like in the case of the tennis racket from the study by Marchak and Hall (2017), they value the material of this specific object.

\section{Limitations and Outstanding Questions}

As with any approach, the essentialist outlook is constrained by a number of limitations. Most obvious is its limited range of application. As we have noted, essentialism works well for objects, but it is less clear how it relates to things that are not clearly objects, such as food or performance art. For instance, does a certain dish embody the essence of its cuisine? Or does some rendering of Shakespeare embody the essence of the play? It is doubtful people think the same way about these as they do about objects.

Another limitation is the lack of direct evidence for essentialism. People do not explicitly formulate an essence and neither can we ever observe one, for the reason that it is a psychological belief. At best then, we have a set of interrelated phenomena (boundary intensification, causal effects, nonobvious properties, etc.) whose existence points toward a single principle. Do these observations necessarily imply essentialism? Perhaps not. The perspective we have here sketched out makes two distinct but related claims. First, it entails a claim of identity: People treat certain valued objects as being individuals, which they distinguish from other identical-looking objects. And second, it involves an essence claim: The belief that the object has an underlying reality, or essence, which can somehow act causally (i.e., "rub off") on others.

This second essence claim might possibly be too strong. Most of the observations which support an essentialist view are also compatible with a more modest minimalist proposal. ${ }^{8}$ Applied to authenticity, ${ }^{9}$ minimalism suggests that the identity of an authentic object is held together by the causal connections between the object's material and its history. For example, people value a real da Vinci painting over a replica because the original has been painted by the great master and the replica has not. The material of the two paintings thus has a different causal history ${ }^{10}$ which causes them to be separate individuals. This is different from the essentialist position, which makes the additional claim that people believe the original has some inner unobservable $\mathrm{Da}$ Vinci essence that pervades the object through and through. 
Although minimalism is intuitively plausible, it fails to account for several observations. First, it is unable to explain the celebrity effect in which an authentic object has elevated worth despite its material having the exact same causal history as its identical noncelebrity counterpart. And second, it is unable to explain people's willingness to touch an ancient monument or their valuation of small pieces of a dinosaur fossil (Jones, 2010; van Gerven et al., 2018). Whether we need essences to explain these findings is still an open question.

Another open question deals with the type of essence involved in authenticity judgments. Do people believe, as Newman (2016) suggests, that essences have no real instantiation in the world but instead reflect "platonic ideals," or are they causal as Gelman (2013) maintains, so that the essences are believed to give the objects their identity. So far, most studies point toward a causal account. But to successfully distinguish between the two types, careful experiments would need to be conducted in which the two accounts are set out against each other.

A third issue that needs to be addressed is the range of authentic objects essentialism applies to. In this article, we have shown that essentialism is already being used to explain how people think about natural kind categories and that it can potentially be extended to cover individual authentic objects. But does this mean that essentialism is universal and therefore applicable to all authentic objects? Few studies have investigated the scope of essentialist beliefs in authenticity, but the ones that did suggest the difference in perceptions of authenticity we sometimes observe between art and ordinary artifacts is only a difference of degree and not a difference of kind (Newman \& Bloom, 2012). Further research could enlighten the contrasts and similarities between perceptions of authenticity in different domains (e.g., artifacts, art, natural objects) and across different cultures.

There is also the question of how the authenticity of objects relates to the authenticity of people. One proposal to which we are wholly sympathetic is that both are instances of the same domain-general phenomenon (Newman et al., 2014). Beliefs about what makes some objects one-of-akind have some striking similarities with people's reasoning about their "true selves" as both display all the telltale signs of essentialism (Newman, 2016; De Freitas, Cikara, Grossmann, \& Schlegel, 2017). Are both types of authenticity driven by the same psychological phenomenon? To our knowledge, this question has not been addressed directly, but we suspect that on a cognitive level, authentic objects might be treated more like persons than ordinary objects.

Finally, there are also the practical implications to consider. The approach we have laid out in this article is primarily intended as a theoretical framework for authenticity. The next logical step will be to test it in practice and make it operational. One way of instrumentalizing our proposal is by creating an essentialist index for objects. We would predict that over a wide range of objects, the degree to which people essentialize these objects should be positively related to their perceived authenticity. If this is correct, such an index could potentially inform professionals such as museum curators about the authenticity of their objects. This would be of great help for both the acquisition of new objects and for deciding which items to set up for display.

\section{Conclusion}

The concept of authenticity has long evaded general consensus, causing the field to break up into a variety of views with different and often problematic definitions. In this theoretical article, we have discussed some of the problems pertaining to objectivism and constructivism. Contrary to the assumptions of objectivism, it was found that authentic objects lack an inner "true nature" which would render them authentic but are rather (in part) the product of people's social constructions. It was also found that constructivism was not without drawbacks either, being extremely fluid and unconcerned with the material dimension of objects. As an alternative, we argued for an essentialist definition of the term by suggesting that the authenticity of objects is rooted in people's natural tendency to ascribe essences to objects they perceive to be authentic. This approach is able to overcome the drawbacks of objectivism by making authenticity dependent on the perceiver and avoids the pitfalls of constructivism by virtue of its empirical rigor. Moreover, by adopting a physical model of how essences persist over time, essentialism is able to explain why people place so much weight on the material dimension of authentic objects. Although not impermeable to critique, we believe essentialism is currently best able to account for the myriad results of other studies. It is our hope that the views outlined in this article will provide a theoretical foundation for further study as well as generate a sustained interest in authenticity more broadly.

\section{Declaration of Conflicting Interests}

The author(s) declared no potential conflicts of interest with respect to the research, authorship, and/or publication of this article.

\section{Funding}

The author(s) received no financial support for the research, authorship, and/or publication of this article.

\section{Notes}

1. Loosely speaking, we consider something an object when it is subject to the principle of cohesion, continuity, and contact. See the work of Spelke (1994) for an elaboration of these principles.

2. As the objectivist has to be able to give a tenable account of the metaphysics of identity, whether or not this can be done 
is a matter to be settled by philosophers and outside the scope of this article.

3. This is somewhat reminiscent of Benjamin's (1969) classic concept of the aura of the original, which he argued diminished in the process of reproduction.

4. This is not the type of objectivist essentialism that is often referred to in tourism research (see Chhabra, 2008).

5. This type of essentialism is known as causal essentialism and is distinct from sortal and ideal essentialism. See Gelman and Hirschfeld (1999) for an overview.

6. This point is somewhat controversial. See Bloom (2007) and Malt and Sloman (2007) for a lively discussion on this issue.

7. See Krøjgaard (2016) for an analogous position, which makes use of a different terminology.

8. This proposal has been put forward by Strevens (2000) and offers an alternative to essentialism. Recent findings, however, speak against a minimalist account (Meyer, Gelman, Roberts, \& Leslie, 2017).

9. We are here concerned with individual objects, not object categories or natural kinds. Strevens's minimalism was restricted to natural kinds only. Strictly speaking, the minimalism we suggest here is slightly different from the one proposed by Strevens (2000).

10. The two paintings can be distinguished because one can be regarded as the causal continuer of the original (Rips, Blok, \& Newman, 2006).

\section{References}

Belhassen, Y., \& Caton, K. (2006). Authenticity matters. Annals of Tourism Research, 33, 853-856.

Belhassen, Y., Caton, K., \& Stewart, W. P. (2008). The search for authenticity in the pilgrim experience. Annals of Tourism Research, 35, 668-689. doi:10.1016/j.annals.2008.03.007

Bendix, R. (1997). In search of authenticity: The formation of folklore studies. Madison: University of Wisconsin Press.

Benjamin, W. (1969). The work of art in the age of mechanical reproduction (H. Zohn, Trans.). In H. Arendt (Ed.), Illuminations: Essays and reflections (pp. 217-251). New York, NY: Schocken Books.

Berger, M. E. (2013). Real, fake or a combination? Examining the authenticity of a Mesoamerican mosaic skull. In A. Geurds \& L. van Broekhoven (Eds.), Creating authenticity authentication processes in ethnographic museums (Vol. 42, 107-136). Leiden, The Netherlands: Sidestone Press.

Beverland, M. (2006). The "real thing": Branding authenticity in the luxury wine trade. Journal of Business Research, 59, 251-258.

Beverland, M. B., \& Farrelly, F. J. (2010). The quest for authenticity in consumption: Consumers' purposive choice of authentic cues to shape experienced outcomes. Journal of Consumer Research, 36, 838-856. doi:10.1086/615047

Bloom, P. (2007). More than words: A reply to Malt and Sloman. Cognition, 105, 649-655. doi:10.1016/j.cognition.2007.04.016

Bruner, E. M. (1994). Abraham Lincoln as authentic reproduction: A critique of postmodernism. American Anthropologist, 96, 397-415.

Buchmann, A., Moore, K., \& Fisher, D. (2010). Experiencing film tourism: Authenticity \& fellowship. Annals of Tourism Research, 37, 229-248. doi:10.1016/j.annals.2009.09.005
Bunce, L. (2016). Appreciation of authenticity promotes curiosity: Implications for object-based learning in museums. Journal of Museum Education, 41, 230-239. doi:10.1080/10598650.201 6.1193312

Chhabra, D. (2008). Positioning museums on an authenticity continuum. Annals of Tourism Research, 35, 427-447. doi:10.1016/j.annals.2007.12.001

Chhabra, D. (2012). Authenticity of the objectively authentic. Annals of Tourism Research, 39, 499-502. doi:10.1016/j. annals.2011.09.005

Christy, A. G., Schlegel, R. J., \& Cimpian, A. (2017, October 24). Why do people believe in a "true self'? The role of essentialist reasoning about personal identity and the self. doi:10.31234/ osf.io/k3jba

Cohen, E. (1988). Authenticity and commoditization in tourism. Annals of Tourism Research, 15, 371-386. doi:10.1016/0160-7383(88)90028-X

Cohen-Aharoni, Y. (2017). Guiding the "real" temple: The construction of authenticity in heritage sites in a state of absence and distance. Annals of Tourism Research, 63, 73-82.

De Freitas, J., Cikara, M., Grossmann, I., \& Schlegel, R. (2017). Origins of the belief in good true selves. Trends in Cognitive Sciences, 21, 634-636.

De Freitas, J., Cikara, M., Grossmann, I., \& Schlegel, R. (2018). Moral goodness is the essence of personal identity. Trends in Cognitive Sciences, 22, 739-740. doi:10.1016/j.tics.2018.05.006

Diesendruck, G., \& Menahem, R. (2015). Essentialism promotes children's inter-ethnic bias. Frontiers in Psychology, 6, 1180. doi:10.3389/fpsyg.2015.01180

Felker, F. M., Hammond, J. D., Schaaf, G., \& Stevenson, J. C. (2014). Existential and object authenticity in Southwestern pottery: Intertwined and complementary. Journal of Material Culture, 19, 93-110. doi:10.1177/1359183513503255

Frazier, B. N., \& Gelman, S. A. (2009). Developmental changes in judgments of authentic objects. Cognitive Development, 24, 284-292. doi:10.1016/j.cogdev.2009.06.003

Frazier, B. N., Gelman, S. A., Wilson, A., \& Hood, B. M. (2009). Picasso paintings, moon rocks, and hand-written Beatles lyrics: Adults' evaluations of authentic objects. Journal of Cognition and Culture, 9, 1-14. doi:10.1163/156853709X414601

Gelman, S. A. (2003). The essential child: Origins of essentialism in everyday thought. New York, NY: Oxford University Press.

Gelman, S. A. (2004). Psychological essentialism in children. Trends in Cognitive Sciences, 8, 404-409. doi:10.1016/j. tics.2004.07.001

Gelman, S. A. (2009). Learning from others: Children's construction of concepts. Annual Review of Psychology, 60, 115-140. doi:10.1146/annurev.psych.59.103006.093659

Gelman, S. A. (2013). Artifacts and essentialism. Review of Philosophy and Psychology, 4, 449-463. doi:10.1007/s13164013-0142-7

Gelman, S. A., \& Davidson, N. S. (2016). Young children's preference for unique owned objects. Cognition, 155, 146-154. doi:10.1016/j.cognition.2016.06.016

Gelman, S. A., \& Hirschfeld, L. A. (1999). How biological is essentialism? In D. L. Medin \& S. Atran (Eds.), Folk biology (pp. 403-446). Cambridge, MA: MIT Press.

Gelman, S. A., \& Markman, E. M. (1987). Young children's inductions from natural kinds: The role of categories and appearances. Child Development, 58, 1532-1541. doi:10.2307/1130693 
Gil-White, F. J. (2001). Are ethnic groups biological "species" to the human brain? Essentialism in our cognition of some social categories. Current Anthropology, 42, 515-553. doi:10.1086/321802

Gjersoe, N. L., Newman, G. E., Chituc, V., \& Hood, B. (2014). Individualism and the extended-self: Cross-cultural differences in the valuation of authentic objects. PLOS ONE, 9(3), e90787. doi:10.1371/journal.pone.0090787

Grayson, K., \& Martinec, R. (2004). Consumer perceptions of iconicity and indexicality and their influence on assessments of authentic market offerings. Journal of Consumer Research, 31, 296-312.

Greif, M. L., Kemler Nelson, D. G., Keil, F. C., \& Gutierrez, F. (2006). What do children want to know about animals and artifacts? Domain-specific requests for information. Psychological Science, 17, 455-459. doi:10.1111/j.14679280.2006.01727.x

Hampp, C., \& Schwan, S. (2015). The role of authentic objects in museums of the history of science and technology: Findings from a visitor study. International Journal of Science Education, Part B, 5, 161-181. doi:10.1080/21548455.2013.875238

Heine, S. J., Dar-Nimrod, I., Cheung, B. Y., \& Proulx, T. (2017). Essentially biased: Why people are fatalistic about genes. In J. M. Olson (Ed.), Advances in experimental social psychology (Vol. 55, pp. 137-192). Cambridge, MA: Academic Press.

Helmore, E. (2017, November 16). Leonardo da Vinci painting sells for $\$ 450 \mathrm{~m}$ at auction, smashing records. The Guardian. Retrieved from https://www.theguardian.com/artanddesign/2017/nov/15/ leonardo-da-vinci-salvator-mundi-auction

Hess, A. (2017). Authenticity, alterations and museum objects: A close encounter with 2LO, the BBC's first radio transmitter. Journal of Material Culture, 22, 281-298. doi:10.1177/1359183517702685

Holtorf, C. (2013). On pastness: A reconsideration of materiality in archaeological object authenticity. Anthropological Quarterly, 86, 427-443. doi:10.1353/anq.2013.0026

Hood, B. M., \& Bloom, P. (2008). Children prefer certain individuals over perfect duplicates. Cognition, 106, 455-462. doi:10.1016/j.cognition.2007.01.012

Jones, S. (2010). Negotiating authentic objects and authentic selves: Beyond the deconstruction of authenticity. Journal of Material Culture, 15, 181-203. doi:10.1177/1359183510364074

Krøjgaard, P. (2016). Keeping track of individuals: Insights from developmental psychology. Integrative Psychological and Behavioral Science, 50, 264-276. doi:10.1007/s12124-015-9340-4

Latham, K. (2009). Numinous experiences with museum objects. Retrieved from https://www.academia.edu/187458/ Numinous_Experiences_with_Museum_Objects

Latham, K. F. (2013). Numinous experiences with museum objects. Visitor Studies, 16, 3-20. doi:10.1080/10645578.20 13.767728

Latour, B., \& Lowe, A. (2010). The migration of the aura or how to explore the original through its fac similes. In T. Bartscherer \& R. Coover (Eds.), Switching Codes: Thinking through digital technology in the humanities and the arts (pp. 257-297). Chicago, IL: The University of Chicago Press.

Lau, R. W. (2010). Revisiting authenticity: A social realist approach. Annals of Tourism Research, 37, 478-498. doi:10.1016/j.annals.2009.11.002

Lee, C., Linkenauger, S. A., Bakdash, J. Z., Joy-Gaba, J. A., \& Profitt, D. R. (2011). Putting like a pro: The role of positive contagion in golf performance and perception. PLOS ONE, 6(10), e26016. doi:10.1371/journal.pone.0026016

Leslie, S. J. (2013). Essence and natural kinds: When science meets preschooler intuition. Oxford Studies in Epistemology, $4,108-165$.

Lowenthal, D. (1992). Counterfeit art: Authentic fakes? International Journal of Cultural Property, 1, 79-104. doi:10.1017/S0940739192000067

Malt, B. C., \& Sloman, S. A. (2007). Category essence or essentially pragmatic? Creator's intention in naming and what's really what. Cognition, 105, 615-648. doi:10.1016/j.cognition.2006.10.001

Marchak, K. A., \& Hall, D. G. (2017). Transforming celebrity objects: Implications for an account of psychological contagion. Journal of Cognition and Culture, 17, 51-72. doi:10.1163/15685373-12342191

Medin, D. L., \& Ortony, A. (1989). Psychological essentialism. In S. Vosniadou \& A. Ortony (Eds.), Similarity and analogical reasoning (pp. 179-195). New York, NY: Cambridge University Press.

Meyer, M., Gelman, S. A., Roberts, S. O., \& Leslie, S.-J. (2017). My heart made me do it: Children's essentialist beliefs about heart transplants. Cognitive Science, 41, 1694-1712. doi:10.1111/cogs. 12431

Michalopoulou, V., Adam-Veleni, P., \& Karapanagiotis, I. (2017). A small bronze statue from the Archaeological Museum of Thessaloniki; exploring its authenticity. STAR: Science \& Technology of Archaeological Research, 3, 303-313. doi:10. 1080/20548923.2018.1441696

Mkono, M. (2012). A netnographic examination of constructive authenticity in Victoria Falls tourist (restaurant) experiences. International Journal of Hospitality Management, 31, 387394. doi:10.1016/j.ijhm.2011.06.013

Nemeroff, C., \& Rozin, P. (1994). The contagion concept in adult thinking in the United States: Transmission of germs and of interpersonal influence. Ethos, 22, 158-186. doi:10.1525/ eth.1994.22.2.02a00020

Newman, G. E. (2016). An essentialist account of authenticity. Journal of Cognition and Culture, 16, 294-321. doi:10.1163/15685373-12342181

Newman, G. E., Bartels, D. M., \& Smith, R. K. (2014). Are artworks more like people than artifacts? Individual concepts and their extensions. Topics in Cognitive Science, 6, 647-662. doi:10.1111/tops.12111

Newman, G. E., \& Bloom, P. (2012). Art and authenticity: The importance of originals in judgments of value. Journal of Experimental Psychology: General, 141, 558-559. doi:10.1037/a0026035

Newman, G. E., \& Bloom, P. (2014). Physical contact influences how much people pay at celebrity auctions. Proceedings of the National Academy of Sciences, 111, 3705-3708. doi:10.1073/ pnas. 1313637111

Newman, G. E., \& Dhar, R. (2014). Authenticity is contagious: Brand essence and the original source of production. Journal of Marketing Research, 51, 371-386. doi:10.1509/ jmr.11.0022

Newman, G. E., Diesendruck, G., \& Bloom, P. (2011). Celebrity contagion and the value of objects. Journal of Consumer Research, 38, 215-228. doi:10.1086/658999

Prentice, D. A., \& Miller, D. T. (2007). Psychological essentialism of human categories. Current Directions in 
Psychological Science, 16, 202-206. doi:10.1111/j.14678721.2007.00504.x

Reisinger, Y., \& Steiner, C. J. (2006). Reconceptualizing object authenticity. Annals of Tourism Research, 33, 65-86. doi:10.1016/j.annals.2005.04.003

Rhodes, M., \& Gelman, S. A. (2009). Five-year-olds' beliefs about the discreteness of category boundaries for animals and artifacts. Psychonomic Bulletin \& Review, 16, 920-924. doi:10.3758/PBR.16.5.920

Rickly-Boyd, J. M. (2012a). Authenticity \& aura: A Benjaminian approach to tourism. Annals of Tourism Research, 39, 269289. doi:10.1016/j.annals.2011.05.003

Rickly-Boyd, J. M. (2012b). Lifestyle climbing: Toward existential authenticity. Journal of Sport \& Tourism, 17, 85-104. doi $: 10.1080 / 14775085.2012 .729898$

Rips, L. J., Blok, S., \& Newman, G. (2006). Tracing the identity of objects. Psychological Review, 113, 1-30. doi:10.1037/0033295X.113.1.1

Rosner, D. K., \& Taylor, A. S. (2012). Binding and aging. Journal of Material Culture, 17, 405-424. doi:10.1177/135918351 2459630

Rossi, M. (2010). Fabricating authenticity: Modeling a whale at the American Museum of Natural History, 1906-1974. Isis, 101, 338-361. doi:10.1086/653096
Sandis, C. (2016). An honest display of fakery: Replicas and the role of museums. Royal Institute of Philosophy Supplements, 79, 241-259. doi:10.1017/S1358246116000163

Spelke, E. (1994). Initial knowledge: Six suggestions. Cognition, 50, 431-445. doi:10.1016/0010-0277(94)90039-6

Strevens, M. (2000). The essentialist aspect of naive theories. Cognition, 74, 149-175. doi:10.1016/S0010-0277(99)00071-2

Strohminger, N., Knobe, J., \& Newman, G. (2017). The true self: A psychological concept distinct from the self. Perspectives on Psychological Science, 12, 551-560. doi:10.1177/1745691616689495

Tarlowski, A. (2018). Ontological constraints in children's inductive inferences: Evidence from a comparison of inferences within animals and vehicles. Frontiers in Psychology, 9, 520. doi:10.3389/fpsyg.2018.00520

Trilling, L. (1972). Sincerity and authenticity. London, England: Oxford University Press.

van Gerven, D., Land-Zandstra, A., \& Damsma, W. (2018). Authenticity matters: Children look beyond appearances in their appreciation of museum objects. International Journal of Science Education, Part $B, 8,325-339$. doi:10.1080/21548455.2018.1497218

Wang, N. (1999). Rethinking authenticity in tourism experience. Annals of Tourism Research, 26, 349-370. doi:10.1016/ S0160-7383(98)00103-0 